\title{
Novas Tecnologias Educacionais: a Elaboração e Apresentação de um Livro Digital de Histologia
}

\author{
New Educational Technologies: The Elaboration and \\ Presentation of a Digital Book of Histology
}

\author{
Daniele Beatriz Leite Silva \\ Universidade Federal do Espírito Santo \\ Larissa Lima Liqui \\ Universidade Federal do Espírito Santo \\ Paula Mello Pacheco \\ Universidade de São Paulo \\ Marco César Cunegundes Guimarães \\ Universidade Federal do Espírito Santo \\ Marcos da Silva Pacheco \\ Universidade Federal do Espirito Santo
}

\begin{abstract}
Resumo: A sociedade se mostra cada vez mais imersa no contexto da informação, interatividade, mobilidade e globalização. No campo educacional a apropriação de novas ferramentas vem mobilizando lentamente educadores na seleção e utilização de ferramentas como livros digitais em suas práticas pedagógicas. Dessa forma, este trabalho teve como objetivo analisar o efeito da apresentação de um livro digital de Histologia sobre estudantes de nível superior. Para isso foi desenvolvido um livro digital de Histologia que foi apresentado para análise e avaliação por estudantes de uma instituição pública e uma instituição privada. A análise dos relatos mostrou que a receptividade pelos alunos quanto a esse recurso é muito boa, entretanto, os livros digitais devem coexistir com o livro tradicional, uma vez que o impresso ainda é um formato bem estabelecido e presente nos hábitos dos estudantes, sugerindo que, embora a transição esteja ocorrendo, ela não foi efetivada.
\end{abstract}

Palavras-chave: Livro digital. Tecnologia na educação. Histologia.

Abstract: Society is increasingly immersed in the context of information, interactivity, mobility and globalization. In the educational field, the appropriation of new tools has been slowly mobilizing educators in the selection and use of technologies such as digital books in their 
pedagogical practices. Thus, this work had as objective to analyze the impact of the presentation of a digital book of Histology with undergraduate students. For that, a digital book of Histology was developed and presented for analysis and evaluation by students of a public institution and a private institution. The analysis of the reports showed that the students 'receptivity to this resource is very good, however, digital books must coexist with the traditional one, since the printed book is still a stablished format and present in students' habits, suggesting that although the transition is taking place, it has not been implemented.

Keywords: Digital books. Technology in education. Histology.

SILVA, Daniele Beatriz Leite; LIQUI, Larissa Lima; PACHECO, Paula Mello; GUIMARÃES, Marco César Cunegundes; PACHECO, Marcos da Silva. Novas Tecńologias Educacionais: a Elaboração e Apresentaçãao de um Livro Digital de Histologia. Informática na Educação: teoria \& prática, Porto Alegre, v. 23, n. 1, p. 81-94, jan./abr. 2020

\section{Introdução}

A sociedade vem vivenciando um enorme avanço no desenvolvimento e utilização de novas tecnologias no cotidiano das pessoas e organizações. Vivemos na era da informação em que a interatividade, mobilidade, interconectividade, globalização e velocidade de acesso são apontadas como características principais. Desta forma, o uso das tecnologias passou a ser um evento intrínseco à nossa sociedade e a utilização de dispositivos eletrônicos vem assumindo papel de destaque no mercado consumidor de livros, ultrapassando a materialidade dos livros impressos e trazendo inclusive questionamentos acerca das transformações das obras frente a originalidade destas (RODRIGUES; CHIMENTI; NOGUEIRA, 2014; LEMOS, 2012). Claramente percebe-se que diversas áreas do saber se constituem e atualizam por meio da tecnologia, entretanto a educação tanto básica quanto superior parece não estar acompanhando o ritmo da modernização tecnológica, não conseguindo atualizar seus modos de produzir, adquirir e armazenar conhecimento (ACKER, 2011; RUTH, 2013; MORÁN, 1999; OZELAME, 2016). Tecnologia e educação podem ser integradas de forma bastante ampla no sentido de que o uso de giz sobre um quadro negro poderia ser considerado como tecnologia, entretanto, novas tecnologias surgem com o intuito de produzir novas formas de se educar que estejam em sintonia com os adventos tecnológicos atuais. Neste estudo pretende-se reconhecer os livros digitais como outra forma de tecnologia da educação, no sentido de estar integrada com o mundo o mundo atual em que o uso de ferramentas eletrônicas de todo tipo fazem parte do cotidiano.

Enquanto as industrias do entretenimento audiovisual se reinventaram e começaram a tomar proveito da tecnologia, as instituições de ensino parecem ter incorporado muito pouco destes benefícios em seu favor. Não é raro nos depararmos com salas de aula tanto no ensino básico quanto no ensino superior que não mudaram muito desde os primórdios da educação 
formal. O espaço sofreu poucas mudanças, algumas certamente proveitosas como o uso de projetores de vídeos e imagens, mas o estudante parece não ter tido muitas oportunidades de se apropriar de novas tecnologias em proveito da aprendizagem, uma vez que apenas recentemente vem surgindo ferramentas eletrônicas destinadas exclusivamente à educação. Assim, cria-se a ideia de que a tecnologia digital, o uso de tablets, smartphones ou qualquer outro dispositivo pertencem apenas ao campo do entretenimento enquanto a educação ainda está restrita a tecnologias e recursos mais antigos como quadros negros e escassos recursos audiovisuais. Desta forma, o livro digital pode apresentar muitas ferramentas que vão além da leitura, sendo uma fonte de múltiplas mídias como áudio, vídeo, animações em três dimensões e de uma infinidade de atividades possíveis que não poderiam ser instrumentalizadas pela utilização de um livro impresso. Assim, o livro digital consegue integrar a familiaridade de um livro tradicional ao mundo digital também já tão familiar nos contextos atuais (CHESSER, 2011; CUTSHALL, BLAND \& MOLLICK, 2012; SOUSA, 2016; LEMOS, 2018). Nesse cenário vemos que embora a educação pareça não acompanhar os avanços tecnológicos, pode-se perceber o movimento de profissionais comprometidos com a educação buscando promover o desenvolvimento do ser humano e, consequentemente, envolvidos na busca de novas formas de se pensar o ensino e a aprendizagem por meio de novas tecnologias (SILVA SOUSA, 2018). A necessidade dessa revisão dos métodos didáticos no sistema de ensino, aliada ao advento de novas tecnologias e sua popularização, especialmente por uso de dispositivos móveis como smartphones trouxe-nos a necessidade de explorar este campo pela elaboração de um livro didático digital em uma área de conhecimento e atuação comum a praticamente todas as carreiras das das ciências biológicas.

O livro didático, desde a sua criação, constituiu um elemento de referência para o processo de ensino-aprendizagem. É uma das principais ferramentas didáticas utilizadas e, em algumas situações, acaba representando a única fonte e meio de informação para alunos e professores. Desta forma, utilizar o livro didático como ferramenta tecnológica que se insere facilmente no contexto dos estudantes contemporâneos poderia se constituir-se numa forma de atualizar modos antigos de se produzir conhecimento. Segundo Falkembach (2005), o uso do computador e das novas tecnologias é um importante agente de transformação no processo educacional, auxiliando no ensino em diversos níveis, visto que são ferramentas inovadoras que podem promovem possibilidades para se trabalhar em sala de aula de uma forma diferente, de modo que possibilitam o desenvolvimento de novas práticas educacionais. A utilização dos livros digitais (ou e-books) é discutido por Sharples (2007), como sendo a aprendizagem móvel que tira partido das novas tecnologias, e utilizá-la na educação tanto básica quanto superior é aproveitar-se dessta tecnologia atualizando a educação colocando-a emparelhada com outros campos que usam tecnologias. A apropriação dessas tecnologias no processo formativo pode ser considerada uma ferramenta importante na medida que o conhecimento humano se atualiza numa velocidade muito superior àquela percebida no século passado, e com isso, novas tecnologias em sala de aula estaria em consonância tanto com a relação entre o ser humano e as ferramentas eletrônicas atuais como com a necessidade de se atualizar conceitos e conteúdos de forma cada vez mais veloz, e mesmo que o professor não faça proveito dos livros digitais de 
modo a atualizar de alguma forma sua prática, o livro digital pode ser uma ferramenta de grande valor para estudo individual em qualquer outro ambiente (PAXHIA, 2011) .

Apesar de ser um novo formato de apresentação e acesso ao conhecimento, poderia se pensar que os livros digitais levarão ao desaparecimento do livro impresso. Na verdade, de acordo com Carvalho (2006), os dois são complementares no processo de disseminação da informação, e a escolha de um ou de outro dependerá do leitor. Logo, a existência de um não significa o desaparecimento do outro. A reconfiguração do livro didático tradicional através da utilização de plataformas digitais possibilita o estímulo dos sentidos e a interação entre leitor e informação. Esta nova realidade é conceituada por Dziekaniak (2010, pag 85):

Essa é a realidade da leitura virtual, um formato que convida o leitor a interagir e a explorar símbolos e palavras que mudam de cor ou que oferecem a facilidade de manuseio com um simples toque; convites para conhecer uma imagem, ouvir um som, aprofundar significados ou conhecer o texto original, ou mesmo outro texto relacionado, são oportunidades permitidas por meio do e-book.

No estudo da Biologia, principalmente no Ensino Superior, a quantidade de informações disponíveis é muito grande e de intensa atualização. Assim, uma obra didática se torna obsoleta rapidamente, exigindo-se novas edições dos mesmos livros em curto prazo. Ainda, muitos livros são publicados sobre um mesmo campo do conhecimento e o estudante então se depara com uma gama enorme de livros, com diversas edições trazendo atualizações variadas, tornando o estudo um processo trabalhoso e caro (ALMEIDA \& NICOLAU, 2013).

Mais especificamente, a Histologia experimentou o desenvolvimento da microscopia permitindo um estudo mais aprofundado de estruturas e aquisição de imagens de melhor qualidade e mais elucidativas. Desta forma, quanto mais ilustrado for o livro, mais rico de informações morfológicas tende a ser, entretanto, uma grande quantidade de imagens encarece grandemente a confecção dos livros didáticos.

Em estudo realizado por Grossi e Fernandes (2014) sobre o uso de telefones celulares como recurso para facilitar o processo de aprendizagem, foi apontado que o uso de tecnologias vem sendo cada vez mais frequente entre os estudantes, tanto de escolas públicas quanto de escolas particulares, constituindo-se como uma ferramenta favorecedora do ensino que possibilita tanto o professor quanto o aluno de assumirem uma nova postura frente ao conhecimento numa lógica dialógica-problematizadora.

Como consequência dessas considerações, este trabalho buscou compreender como a apresentação de um livro digital de Histologia poderia se manifestar como nova forma de aprender e ensinar fazendo uso da tecnologia. Dessa forma, este trabalho teve por objetivo analisar o impacto da apresentação de um livro digital de Histologia a estudantes de uma instituição pública e uma instituição privada de ensino superior. Para isso, desenvolvemos um livro digital de histologia, voltado principalmente para o ensino superior, e a partir dele, analisamos de que forma os estudantes lidam com este tipo de recurso tecnológico, como ocorre sua aceitação, que vantagens e desvantagens são apontadas por estes usuários e como os 
estudantes da área biomédica analisam novas fontes de estudo quando comparadas ao tradicional livro didático.

\section{Metodologia}

\subsection{Elaboração de um livro digital de Histologia}

Para analisar como seria a aceitação de um livro digital de Histologia junto a estudantes de nível superior foi necessária a elaboração de um material totalmente novo e inédito (Figura 1). A elaboração do livro digital foi feita através da análise das principais obras de Histologia disponíveis atualmente para produzir um material que trouxesse atualizações relevantes ao campo de conhecimento. A obtenção de imagens digitais foi realizada a partir de lâminas histológicas pertencentes ao acervo do setor de Histologia do Departamento de Morfologia da Universidade Federal do Espírito Santo, utilizando-se um fotomicroscópio e sistema de captura. A redação do livro digital foi feita pela equipe composta por professores da Universidade, todos com Mestrado e Doutorado em áreas da saúde e por estudantes de graduação em Ciências Biológicas. Posteriormente, o produto final foi inserido no aplicativo utilizado para edição de livros digitais (Ibooks Author, Apple).

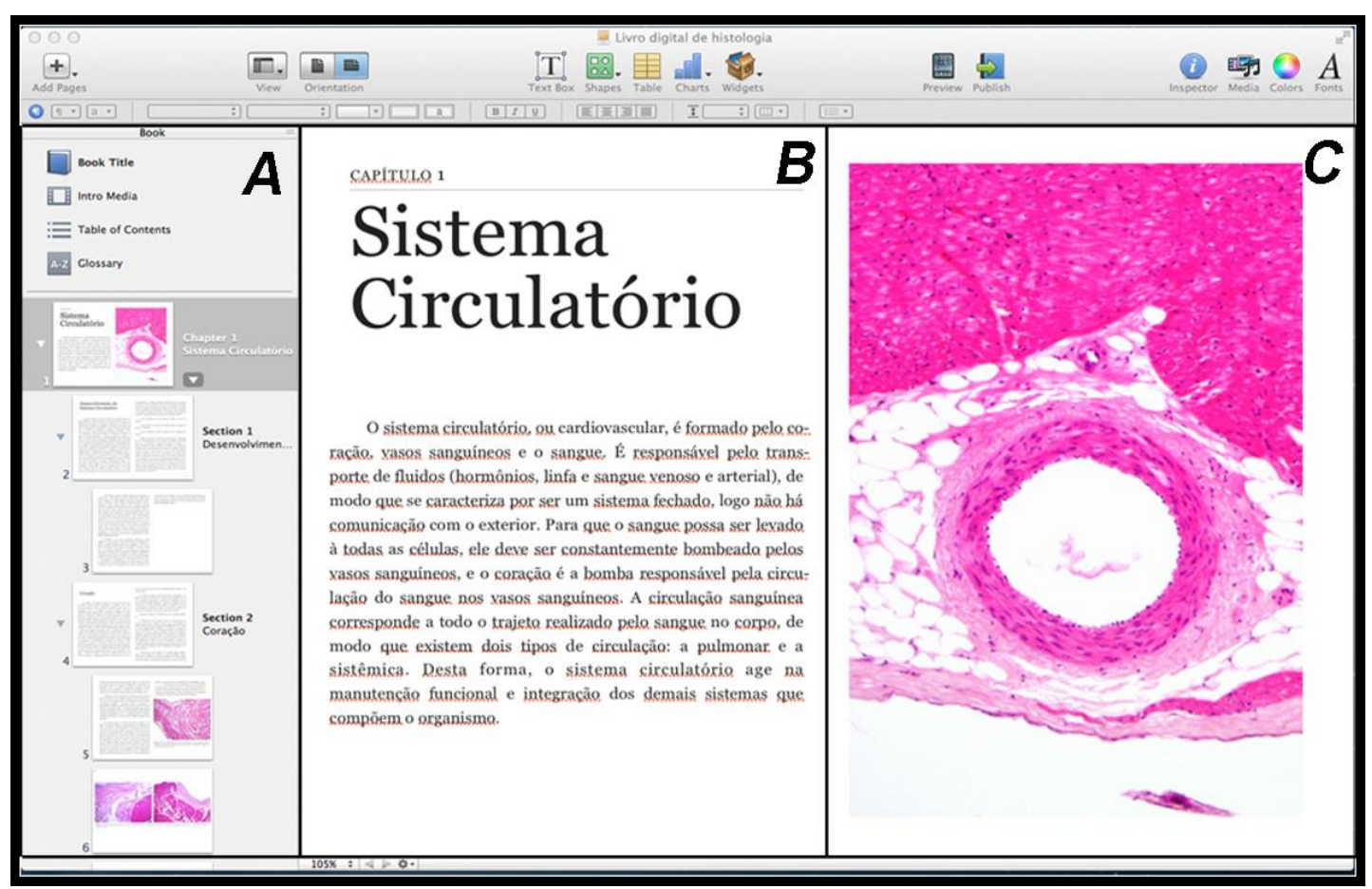

Figura 1: Apresentação do livro digital. A: No campo A pode-se acessar todo o índice do livro, permitindo ir para o capítulo de interesse rapidamente. Há um glossário para o esclarecimento de dúvidas em relação à nomenclatura e conceitos breves. Nesse campo também pode-se observar as páginas do capítulo aberto no campo à direita bem como a relação das figuras. B: O texto do livro digital apresenta a contextualização teórica suscinta, correlacionada com outras áreas do conhecimento atreladas à histologia. C: Apresentação da imagem histológica em alta qualidade e extraída da coleção de lâminas histológicas da Universidade. 


\subsection{Escolha dos Participantes e Avaliação do livro digital}

O relato de caso foi dividido em duas experimentações: A primeira foi a apresentação do livro a turmas visitantes do Museu de Ciências da Vida da Universidade Federal do Espírito Santo (UFES); a segunda, para alunos do 10 Período do curso de Nutrição da mesma Instituição de Ensino Superior. Trata-se de uma escolha de participantes por conveniência, uma vez que os professores autores deste trabalho lecionam no curso de Nutrição e por meio de suas práticas pedagógicas vem percebendo as mudanças na busca por material didático que facilitem a aprendizagem. Ainda, o Museu de Ciências da Vida é um projeto da Universidade Federal do Espírito Santo que conta com a visita de estudantes de diversas instituições, tanto públicas quanto privadas, sendo dessa forma uma importante meio para obtermos participantes universitários com características diferentes da amostra de alunos do curso de Nutrição.

O Museu de Ciências da Vida é produto de um Programa de Extensão Universitária, sem fins lucrativos, que promove a difusão e popularização da ciência relativa ao Corpo Humano. A apresentação do livro foi feita juntamente com a exposição "Corpo Humano: da célula ao homem, arte dos pequenos suspiros" na Galeria de Arte e Pesquisa da Universidade Federal do Espírito Santo, na cidade de Vitória/ES no ano de 2014, organizada pelo próprio museu. Como o agendamento de visitas do museu é acessível ao público, o dia para a exposição do livro foi escolhido propositalmente para coincidir com a visita de uma turma do Ensino Superior de Biomedicina de uma faculdade particular da região. O objetivo inicial da experimentação no Museu de Ciências da Vida foi a disponibilização do livro digital neste espaço, isto é, determinar se a inserção do livro no Museu seria aceita e adequada. Foram entrevistados, ao todo, 22 visitantes do museu, todos do mesmo grupo de visitantes de uma única instituição privada de ensino superior. A idade dos estudantes variou de 18 a 32 anos (média: 26,32 anos), sendo 14 estudantes do sexo feminino e 7 estudantes do sexo masculino. Os entrevistados no Museu e do curso de Nutrição, além de responderem ao questionário com perguntas fechadas também responderam a uma questão aberta sobre o Livro Digital de Histologia.

O Curso de Nutrição da UFES, na cidade de Vitória, foi escolhido por ser um curso da área biomédica que utiliza livros de Histologia no primeiro e no segundo períodos da formação. Foram entrevistados ao todo 24 estudantes, com idades variando entre 18 anos e 26 anos (média 20,02 anos), sendo 21 estudantes do sexo feminino e 3 estudantes do sexo masculino. Os estudantes responderam perguntas relacionadas aos livros digitais de um modo geral e relacionadas ao Livro Digital de Histologia. Todos os estudantes de ambas as instituições relataram utilizar algum tipo de dispositivo para consulta de livros digitais (computador, tablets e/ou smartphones). A vantagem em se utilizar estudantes de instituições diferentes, e de regimes administrativos diferentes (pública e privada) é a de se verificar se tais diferenças produziram alguma percepção alterada, mesmo sabendo-se que ambos grupos têm acesso a livros em suas bibliotecas e são proprietários de aparelhos eletrônicos que possibilitam a leitura de livros digitais.

A apresentação incluiu explicações tais como: o que motivou a escrita do mesmo, sua estrutura, quais os recursos que o diferenciam de um livro convencional ou de algum outro livro digital, e exposição de algumas imagens histológicas contidas nos capítulos. Após esse momento, 
os visitantes puderam tirar alguma dúvida ou ver alguma parte específica do material apresentado.

Para se avaliar o papel da introdução de novas tecnologias para o ensino e se ter a dimensão da real aplicabilidade do livro concebido para este estudo, além de se conhecer a respeito de sua aceitação, foi escolhida como abordagem metodológica o estudo de caso, que pode ser definido como o exame de um fenómeno específico, tal como um programa, um acontecimento, uma pessoa, um processo, uma instituição, ou um grupo social; ou então, como uma investigação empírica que investiga um fenómeno contemporâneo dentro do seu contexto real de vida (SARMENTO, 2011)

O fenômeno contemporâneo analisado neste estudo foi, na sua forma mais simples, o próprio livro digital de histologia, que, ao ser analisado "dentro do seu contexto real de vida", ou seja, na própria sala de aula, pelos próprios alunos tornou possível identificar seu papel como facilitador do processo de aprendizagem, e permitiu verificar o nível de aceitação do livro pelo público-alvo.

\subsection{Utilização de Questionário de avaliação}

Em ambos os casos, ao final da apresentação, os entrevistados foram convidados a responder a um questionário sobre o livro digital elaborado pelo nosso grupo de pesquisa em uma abordagem quantitativa, pelo emprego de uma escala do tipo Lickert que abrangia perguntas tanto relacionadas à utilização de livros digitais como uma ferramenta de estudo, considerando-se todas as possíveis facilidades e vantagens destes, quanto ao livro digital de Histologia, especificamente. $\mathrm{O}$ instrumento de coleta de dados utilizado foi um questionário do tipo fechado com respostas também fechadas, no qual o entrevistado seleciona a opção que mais se adequa a sua opinião. Este tipo de questionário facilita a categorização das respostas para posterior análise, além de conferir rapidez e facilidade às respostas. Além disso, os entrevistados foram incentivados também a entregar, juntamente com o questionário, um pequeno relato escrito sobre sua opinião a respeito do livro.

\subsection{Análise dos dados das entrevistas}

Para a análise dos dados, procedeu-se ao tratamento estatístico descritivo e inferencial utilizando-se software SPSS. Os relatos dos estudantes foram categorizados por aproximação semântica utilizando-se a análise de conteúdo (BARDIN, 2008), que permitiu explorar as avaliações, julgamentos e opiniões dos indivíduos a partir do que fora enunciado nas entrevistas. Estas informações foram transformadas por recorte, enumeração e agregação. Foi feita, por fim, uma tabulação de frequência absoluta $(\mathrm{N})$ e relativa $(\%)$.

\section{Resultados e Discussão}

Os estudantes do curso de Nutrição da UFES avaliam os livros digitais positivamente para auxiliá-los em seus estudos, uma vez que $91,66 \%$ destes consideram livros digitais boas 
ferramentas de estudo e, entre os motivos que favorecem esta posição, está o fato de que os livros digitais são mais facilmente transportados quando comparados aos livros tradicionais. Ressaltam que precisam levar diversos livros para estudar, e que estes são volumosos e pesados, de maneira que o livro digital se mostra vantajoso por ser portátil. Além disso, 79,16\% dos estudantes entrevistados concordam com a ideia de que livros digitais são mais fáceis de serem acessados, podendo-se consultar muitos livros em pouco tempo. Outra vantagem apontada pelos estudantes $(58,33 \%)$ é o fato de livros digitais normalmente apresentarem mais figuras e esquemas visuais do que livros impressos, uma vez que não se tem elevados custos de impressão. Assim, foi possível observar que a facilidade se se obter material didático, preços reduzidos em comparação ao material impresso, os recursos interativos e a portabilidade foram as principais vantagens que os entrevistados associaram ao livro digital. Ainda, foi apontado como um fator favorecedor do uso de livros digitais o fato destes serem, de um modo geral, mais resumidos que os livros tradicionais, permitindo uma consulta mais dinâmica, obtendo-se a informação de interesse de modo rápido e eficaz. Os estudantes acreditam que uma característica dos livros digitais seria sua apresentação mais sintética quando comparada a dos livros tradicionais, uma vez que $54,16 \%$ dos entrevistados pontuaram esta característica como fundamental.

É importante ressaltar que mesmo afirmando que os livros digitais devem ser sintéticos, os estudantes entrevistados discordaram da afirmação de que os livros digitais deveriam ser apenas utilizados como apoio, mas indicaram que poderiam ser a fonte principal de estudo. Apesar da apresentação mais sintética, os livros digitais permitem que se acrescente uma diversidade maior de conteúdo, como vídeos, áudios, animações e hiperlinks- que enriquecem e complementam o texto, além de estimular o usuário a interagir com o material apresentado. Ao serem questionados sobre o fato de um livro digital nunca ser usado como fonte principal, $66,66 \%$ dos entrevistados discordaram, demonstrando que os livros impressos poderão muito brevemente perder espaço para outras possibilidades de acesso ao estudo.

Apesar das diversas formas de apresentação de um livro, este não perde a sua função; isto é, os seus elementos podem apresentar variações ao longo do tempo de acordo com o desenvolvimento da sociedade, entretanto vale destacar que o livro permanece como um suporte de informação e leitura. O livro e as práticas de leitura passaram por reformas ao longo dos séculos e, à medida que a estrutura física do livro passava por transformações, as práticas de leitura e funções do livro assumiam características distintas. Neste sentido, o livro digital pode ser concebido de diversas formas que variam desde considerá-lo apenas como um livro qualquer impresso transportado para uma tela, até quem o perceba como uma ferramenta que vai muito além de uma sequência de textos, considerando-o como uma fonte de múltiplas mídias como áudio, vídeo, animações em três dimensões e de uma infinidade de atividades possíveis que não poderiam ser instrumentalizadas pela utilização de um livro impresso. Assim, o livro digital consegue integrar a familiaridade de um livro ao mundo digital também já tão familiar nos contextos atuais (CHESSER, 2011; CUTSHALL, BLAND \& MOLLICK, 2012; SOUSA, 2016; LEMOS, 2018). 
Sobre a possibilidade de se estudar mais com um livro digital, uma vez que ele apresenta as vantagens de ser mais barato, mais fácil de transportar e mais bem ilustrado, apenas 45,83\% dos entrevistados afirmaram que sim, indicando que o livro digital, embora um dispositivo inovador e com vantagens observáveis, não foi considerado pelos estudantes como um substituto para tornar o estudo mais eficaz. De modo semelhante, 45,83\% dos entrevistados ao serem questionados sobre a possibilidade de preferir livros impressos afirmaram que sim, indicando que a utilização de livros digitais ainda não se tornou um hábito entre os estudantes universitários entrevistados. Segundo relatos dos próprios entrevistados, a preferência pelo livro impresso se dá pela necessidade de contato com o material de estudo, pois durante toda a vida acadêmica utilizaram livros impressos para estudar; portanto, já existe uma interação estabelecida através do contato direto do estudante com o livro impresso.

Em relação ao interesse em adquirir um livro impresso mesmo já possuindo uma cópia digital, apenas 24,99\% afirmaram a possibilidade de fazer tal compra, e 66,66\% dos entrevistados discordam que se deve comprar um livro impresso se tiver a opção de adquirir um livro digital por um preço mais baixo. É interessante ressaltar que mesmo dispostos a adquirir livros digitais em detrimento de livros impressos, especialmente por conta do preço, apenas $12,5 \%$ dos entrevistados afirmaram procurar livros digitais com frequência. Isso se deve ao fato da escassa divulgação dos livros digitais, além de que ainda há dificuldades na inserção de dispositivos eletrônicos nas salas de aula; fatos também relatados pelos próprios entrevistados.

Rodrigues et al. (2014) ressaltam que o livro digital traz benefícios, como a possibilidade de atualizações sem custo de reimpressão, o que no livro impresso acaba produzindo novas edições e consequentemente tornando as edições antigas obsoletas e sem valor de mercado. Em adição, o acesso pode ser feito através de diversos dispositivos sem custo de distribuição, fretes, etc, e o mais interessante é o fato de que o livro digital se traduz em um material que se adapta ao estudante, especialmente pela facilidade de acesso por diferentes dispositivos, pela portabilidade e pela interface de utilização, ao invés do que acontece com o livro impresso no qual o estudante deve se adaptar a ele.

Após serem apresentados ao Livro Digital de Histologia os estudantes foram questionados sobre a qualidade do material e $95,83 \%$ concordou se tratar de uma obra excelente para a consulta sobre o tema abordado, 95,83\% apontaram as figuras como sendo de boa qualidade e úteis para a compreensão do conteúdo apresentado. Perguntados se caso fossem estudar os assuntos apresentados, fariam deste livro o primeiro material de consulta, 79,16\% responderam concordar com esta afirmação. O texto foi considerado agradável e interessante para 95,83\%, claro e acessível para 87,5\%. Um grande número de estudantes também recomendaria o Livro Digital de Histologia para colegas que precisassem deste material como fonte de estudo.

Tais dados mostram que a ideia de se ter um livro digital é bastante positiva, e esta ainda se reforça na presença do mesmo que ao poder ser visualizado, manuseado, e explorado, permite aos estudantes reconhecerem nele uma fonte de estudo eficaz, acessível e mais barata. Ainda por conta da maior disponibilidade do livro impresso, e por um condicionamento cultural manifesto desde a infância, a escolha por este material parece ser a opção mais óbvia, entretanto, podemos perceber neste estudo uma nova tendência no campo da educação que é a 
introdução de novas tecnologias a serviço de uma educação mais dinâmica e integrada à realidade digital vivida cotidianamente.

A aplicação dos mesmos questionários no Museu de Ciências da Vida confirmou os dados coletados nas salas de aula do curso de Nutrição. A grande maioria (90,90\%) considera o livro digital uma boa fonte de auxílio no estudo. Também ressaltam a facilidade de transporte $(77,27 \%)$ e uma maior riqueza de figuras (63,63\%). A apresentação do Livro Digital de Histologia obteve impressões semelhantes às das que foram encontradas na turma de Nutrição, mostrando uma boa receptividade no meio universitário em relação a fontes alternativas aos livros didáticos impressos. De modo geral, os visitantes ressaltaram a qualidade das figuras presentes no livro, além da possibilidade de interagir com as mesmas - como aplicar zoom às imagens ou exibição de explicações em determinados pontos da figura.

Os questionanários com perguntas abertas foram analisados através da análise de conteúdo, e consistiu em três procedimentos: codificaçao de dados, categorização e inferência (Bardin, 2004). Para o processo de codificação de dados foi feita a leitura flutuante das respostas obtidas afim de se perceber que categorias emergiram para que fossem então categorizadas. Fonseca Júnior (2011) ressalta que a análise de conteúdo refere-se a um método de análise das ciências humanas e sociais que possibilita a investigação de fenômenos e sua melhor compreensão. A análise de conteúdo operou na confirmação das hipóteses acerca das vantagens que um livro digital poderia trazer para os estudantes, no ambiente escolar mas também em outros espaços por conta do fácil acesso ao material. As categorias observadas por meio da análise de conteúdo foram organizadas na tabela 1 que apresenta também a frequencia com que essas categorias emergiram durante o processo de codificação.

Tabela 1 - Conteúdo das respostas às perguntas abertas

\section{Categorias}

Valorização das imagens histológicas

Conteúdo abrangente (não restrito apenas à Histologia)

Dá importância à informação independente do formato (físico ou digital)

Ressalta a tecnologia como forma de facilitar o acesso e o transporte

Prefere livros digital por estar acostumado com o formato
Frequência

$\%$

\section{Fonte: Arquivo do grupo de pesquisa}

A proposição de fazer comentários abertos sobre a experiência do Livro Digital de Histologia permitiu com que diferentes respostas fossem obtidas sem um direcionamento por 
parte dos pesquisadores. As categorias que emergiram de maneira mais pronunciada foram a valorização das imagens histológicas e o conteúdo abrangente, não limitado apenas à Histologia, como é frequente nas publicações universitárias. Ainda, acerca das opiniões, os estudantes ressaltaram a tecnologia como forma de facilitar o acesso aos livros digitais e o transporte. Ainda, foi mencionada a preferência pelo livro impresso, por uma questão de costume. Como exemplo para as categorias observadas pela codificação e categorização do conteúdo obtido com as entrevistas algumas enunciação são destacadas.

A valorização das imagens, presente em 47,5\% dos comentários abertos pode ser exemplificada no comentário de uma estudante de Biomedicina, visitante do Museu, M.L.B., de 23 anos: "Os livros atuais de histologia não têm muitas imagens. Aí a gente tem que ficar pegando vários atlas, pesquisando na internet, e mesmo assim às vezes não conseguimos uma figura boa ". Ainda, outra estudante da mesma instituição aponta: " Nossa, é muito mais legal ver tudo assim ao vivo, do que os desenhos dos livros. Assim eu consigo visualizar melhor como as células são e é uma imagem difícil de esquecer ", referindo-se ao fato de o Livro Digital de Histologia trazer muitas fotos reais do tecido em vez de esquemas.

Quanto à possibilidade de um livro digital poder compor um conteúdo mais abrangente, a estudante L.M.P., de 19 anos comentou: "Eu gostei porque vocês conseguiram juntar embriologia e histologia num material só, então facilita muito na hora de estudar. Vocês também colocaram alguns tópicos de regeneração do órgão, que é algo recente nos estudos".

Sobre as vantagens quanto ao uso da tecnologia auxiliando o processo de aprendizagem, a estudante F.M.S., de 24 anos ressaltou: "Ah, eu costumo ler mais no meu computador e no celular ultimamente. Acho que é porque é mais fácil de carregar e eu consigo ler sobre vários assuntos numa velocidade maior. E hoje esses livros digitais têm recursos muito legais, porque dentro de um texto você pode ter acesso a um vídeo ou ver o significado de uma palavra, tudo na hora, sabe? É bem mais fácil, eu acho ", mostrando uma tendência de se poder, por meio dos livros digitais, carregar consigo muitos livros e poder acessá-los rapidamente por meio de telefones celulares ou outros aparelhos. As principais vantagens dos livros digitais representam a nova realidade da leitura, na qual é possível interagir com imagens e símbolos, explorar as palavras, além da facilidade de transportá-los e acessá-los facilmente a partir de diversos dispositivos eletrônicos.

Nossos dados estão de acordo com os achados de Paxhia (2011), que mostrou que os livros digitais apresentam como características consideradas vantajosas pelos estudantes a portabilidade, uma vez que se pode ter em mãos vários livros ao mesmo tempo; a facilidade de comprar, pois os livros podem ser adquiridos pela internet, de forma mais barata, rápida e sem a necessidade de se contar com disponibilidade em estoque ou tempo de entrega e valor de frete, o que essencialmente se configura como opção econômica e prática (PAXHIA, 2011).

Uma questão que se apresenta ao se comparar os livros impressos aos livros digitais é o fato destes últimos poderem ser considerados de fato como livros, e a partir da aceitação desta ideia, seria necessário que todos os sujeitos envolvidos na produção, divulgação, aquisição e utilização deste material gradativamente aceitassem esta revolução da produção de material acadêmico. Não basta apenas considerar a opinião dos estudantes, ou seus pais, que seriam de 
fato os consumidores finais deste produto, mas toda a cadeia que envolve sua produção deveria se engajar neste processo. Segundo Rodrigues e colaboradores (2014) os pais e alunos deveriam perceber o livro como uma fonte de solução e diferenciação, ou seja, considerar os livros digitais como uma opção econômica, prática e acessível; os professores deveriam adotá-lo para que fossem utilizados como facilitadores do processo de ensino; as escolas precisariam acreditar neste material como uma inovação e as editoras precisariam ver um meio de obter lucros. Todos os elementos desta cadeia deveriam ter participação do processo, o que de outra forma poderia produzir o fracasso desta inovação. Muito embora a tecnologia se apresente como um mecanismo de facilitar o acesso rápido, preciso, pontual e menos dispendioso ao livro didático, ainda percebemos alguma resistência por parte dos estudantes, que afirmam preferirem o livro impresso por uma questão de hábito, já que vem desde a educação infantil estudando por meio deste tipo de material. Este posicionamento pode ser percebido nos comentários como: "Olha, eu prefiro o livro normal, o impresso. Gosto de ter o livro na minha mão, me sinto mais à vontade. ", afirma um visitante do Museu, e " Assim, eu não estou muito acostumada a ler livros no meu computador... eu gosto mais de ter o livro impresso, acho que é mais por costume", pontuou a estudante A.S.N., de 21 anos, visitante do museu.

Apesar de todas as vantagens apresentadas neste trabalho sobre os livros digitais, Acker (2011) discute que, dentre os fatores que tornam o livro didático digital uma ferramenta ainda em processo de aceitação está o fato de as escolas relutarem na sua adoção, o custo com a informatização do sistema de bibliotecas e com o treinamento dos professores, que normalmente não têm tempo de incorporar novas formas de ensino e acabam ficando restritos ao livro didático, que, muitas vezes, em vez de ser uma ferramenta acaba sendo o cerne do processo de aprendizagem (ACKER, 2011; RUTH, 2013; MORÁN, 1999; OZELAME, 2016).

\section{Conclusão}

Através desta pesquisa foi possível observar que um dos principais empecilhos para a utilização do livro digital é ainda o hábito de se utilizar material impresso para estudar. Para muitos, o hábito da leitura ainda está relacionado ao livro físico, pois a nossa sociedade ainda está arraigada na ideia de que um livro é "um conjunto de folhas impressas e reunidas em volume encadernado ou brochado" (Enciclopédia e Dicionário Ilustrado Koogan/Houaiss, 1995).

Não foi objetivo desse trabalho determinar se essa substituição irá de fato acontecer. A priori, essa questão é muito recente e necessita de mais reflexão e estudos, não existindo uma resposta final a respeito do fim do livro impresso. É preciso que haja mais pesquisas científicas analisando os aspectos constituintes do processo de utilização do livro e as suas possíveis implicações, vantagens e desvantagens, para a leitura.

Não é mais possível relevar todas as transformações tecnológicas pelas quais estamos passando. A experimentação com o livro digital nos mostrou que a maioria dos estudantes entrevistados gostariam de tê-lo para os estudos, mas como um instrumento adicional, e não como substituição ao livro tradicional. O que pode ser percebido é que, por enquanto, é necessária a coexistência desses dois recursos. Em cada momento do aprendizado, um dos livros 
servirá para propósitos distintos; eles se complementarão e fornecerão uma base mais completa tanto para alunos quanto para professores.

Paralelamente, o que devemos defender é o papel do professor nessa mudança. Mediador entre o conhecimento e o aluno, sua função não pode se findar com a maior utilização de dispositivos eletrônicos. Mesmo sendo recursos vantajosos também para o professor, entender como estas mudanças afetarão a escola e modificarão seu papel na sala de aula passa a ser um grande desafio para os docentes.

\section{Referências}

ACKER, S. R. Chapter 6: Digital textbooks in SUE, P. The No Shelf Required Guide to E-book Purchasing. Library Technology Reports, v.47, n.8, p 41-51, 2011.

ALMEIDA, F.; NICOLAU, M. A reconfiguração do livro didático em versão digital: uma ideia de sustentabilidade. Revista Temática, n.1, 1-10, 2013.

BARDIN, L. Análise de conteúdo (L. Reto \& A. Pinheiro, Trad.). São Paulo: Edições 70/Livraria Martins Fontes, 2008.

CARVALHO, K. O admirável mundo da informação e do conhecimento: livro impresso em papel e livro eletrônico, Biblios: Revista de Bibliotecnología y Ciencias de la Información. v.7, n. 4, 2006.

CHESSER, W. D. Chapter 5: The e-textbook revolution in SUE, P. The No Shelf Required Guide to E-book Purchasing, Library Technology Reports, v.47, n.8, p 28-40, 2011.

CUTSHALL, R. C., BLAND, E. M., \& MOLLICK, J. S. Use of an e-textbook and web-based homework for an undergraduate business course: Students' perceptions, Journal of the Academy of Business Education. v.13, p 1-15, 2012.

DZIEKANIAK, G.V. et al. Considerações sobre o e-book: do hipertexto à preservação digital, Biblos. v.24, n.2, p. 83-99, 2010.

FALKEMBACH, G.A.M. Concepção e desenvolvimento de material educativo digital, Novas Tecnologias na Educação. v.3, n.1, p. 1-15, 2005.

GROSSI, M. G.R; FERNANDES, L. C. B. E. Educação e tecnologia: o telefone celular como recurso de aprendizagem, EccoS - Rev. Cient., São Paulo, n. 35, p. 47-65, set./dez. 2014.

KOOGAN, A.; HOUAISS, A. Enciclopédia e dicionário ilustrado. 4ed, 1995.

LEMOS, A. Cibercultura. Tecnologia e vida social na cultura contemporânea. 2002.

LEMOS, A. Dispositivos eletrônicos de Leitura. Comunicação, mídia e consumo. vol. 9 n. 24 p. 115-131. 2012.

LEMOS, A. Cibercultura e Mobilidade: a Era da Conexão, Razón y Palabra, Vol. 22. 107- 133. 2018.

MORÁN, J.M. Uso da Internet no ensino transforma o papel do professor, exigindo dele maior atenção para orientação e acompanhamento do aluno, Revista Comunicação \& Educação. n.14, 17-26, 1999.

OZELAME, D.M. Concepções de professores sobre o uso de tecnologias digitais nas escolas do ensino fundamental do paraná: o caso do ensino das ciências da natureza, HOLOS, Ano 32, Vol. 2. 389-401. 2016.

PAXHIA, S. The challenges of higher education digital publishing, Publishing Research Quarterly. v.27, n.4, p. 321-326, 2011. 
RODRIGUES, M. A. S.; CHIMENTI, P. C. P. S.; NOGUEIRA, R. R. Adoção de inovações em mercados em rede: uma análise da introdução do livro didático digital no Brasil, Revista de Administração e Inovação. $v$. 11, n.4, p.159-192, 2014

RUTH, K. J. Texts that change schools, Independent School, v.72, n.4, p 50-55, 2013.

SARMENTO, M. J. O Estudo de Caso Etnográfico em Educação in N. ZAGO; M. PINTO DE CARVALHO; R. A. T. VILELA (Org.) Itinerários de Pesquisa - Perspectivas Qualitativas em Sociologia da Educação. p.137 179, Rio de Janeiro: Lamparina (2a edição), 2011.

SHARPLES, M.; TAYLOR, J.; \& VAVOULA, G. A. Theory of Learning for the Mobile Age. In ANDREWS, R; HAYTHORNTHWAITE, C. (eds.) The Sage Handbook of Elearning Research. London: Sage, pp. 221-247, 2007.

SILVA SOUSA, K. A Comunicação on line no ensino superior como recurso didático na pesquisa em educação, Revista Observatório. v. 4, n. 4, p. 550-570, 2018.

SOUSA, A. I. P. Analfabetismo Digital na Educação, EaD \& Tecnologias Digitais na Educação. n 5, Vol. 4. $52-58,2016$

Recebido em julho de 2019.

Aprovado para publicação em fevereiro de 2020

Daniele Beatriz Leite Silva

Universidade Federal do Espírito Santo - UFES, Brasil, danni.bia@hotmail.com

Larissa Lima Liqui

Universidade Federal do Espírito Santo - UFES, Brasil, larissa.liqui@gmail.com

Paula Mello Pacheco

Programa de Pós Graduação em Ciencias da Reabilitação

Universidade de São Paulo - USP, Brasil, paulampacheco@yahoo.com.br

\section{Marco César Cunegundes Guimarães}

Departamento de Morfologia

Universidade Federal do Espírito Santo - UFES, Brasil, marco.cunegundes@gmail.com

\section{Marcos da Silva Pacheco}

Departamento de Morfologia

Universidade Federal do Espírito Santo - UFES, Brasil, marcosbiologia@yahoo.com.br 